\title{
LA INSCRIPCIÓN DE ACCIONES EN LAS SOCIEDADES ANÓNIMAS CERRADAS. REFLEXIONES EN TORNO A SU REGULACIÓN
}

\section{Fernanda VÁSQUez Palma*}

\section{1) INTRODUCCIÓN}

Las sociedades anónimas presentan un mismo marco jurídico para regular sus distintos tipos, a pesar de las diferencias que entre ellas habitan. Ello nos fuerza a reflexionar sobre las formas de revertir los posibles desajustes que se generan entre las sociedades y la necesidad de mantener un único estatuto jurídico para todas ellas.

En el presente comentario analizaremos una sentencia reciente que, rechazando un recurso de casación en el fondo, subraya la necesaria inscripción de las acciones en una sociedad anónima cerrada como requisito sine qua non para el ejercicio de los derechos del accionista. Este fallo será el hilo conductor por medio del cual revisaremos distintas materias y fallos ligadas a lo anterior, las que desde una visión conjunta nos permitirá observar los bemoles de la especial arquitectura normativa de este tipo societario, en contraposición a otros de similar naturaleza.

\section{2) Caso: "González Tassara con Sociedad anónima Tulor". EXPOSICIÓN DE LOS HECHOS Y SENTENCIA PRONUNCIADA ${ }^{1}$}

En estos autos, Rol N³3.505-2008, seguidos ante el Tercer Juzgado Civil de Calama, compareció doña Trissy Figueroa Rivera, abogada, en representación de don Claudio González Tassara, y dedujo demanda en juicio ordinario de cobro de pesos, en contra de Tulor Sociedad Anónima, solicitando se condene a la sociedad demandada al pago de la suma de dinero que corresponda a los dividendos de la misma, por los ejercicios comerciales de los años 2005 a 2008, más reajustes, intereses y costas. Funda su acción señalando que su representado es socio de Tulor S.A., desde la época de su constitución en el año 1993, con una participación en la misma del 42,5\%. Ańade que desde sus inicios hasta el $1^{\circ}$ de julio,

\footnotetext{
* Doctora en Derecho por la Universidad Complutense de Madrid. Profesora Asociada de Derecho Privado, Facultad de Ciencias Jurídicas y Sociales de la Universidad de Talca. Directora del Departamento de Derecho Privado y Ciencias del Derecho de la Facultad de Ciencias Jurídicas y Sociales, Universidad de Talca. E mail: mfvasquez@utalca.cl

1 Corte Suprema. 12 de abril de 2012. Rol N 7384-11 "González Tassara, Claudio c/ Sociedad Anónima Tulor”. Primera Sala, MJJ31765.
} 
de 2005, cumplió en ella funciones de gerente general. Empero, desde este último año a la fecha de la demanda (11 de diciembre de 2008), el actor no ha recibido las sumas que corresponden al pago de dividendos de la empresa, lo que obliga a la interposición de la presente demanda.

La sociedad demandada, contestó la demanda, solicitando su íntegro rechazo, con costas e interpuso, asimismo, demanda reconvencional. Expone que los hechos en los que funda la contraria sus pretensiones son falsos, parciales e incompletos y solo dan cuenta de su tentativa de lucrar ilícitamente y perjudicar a la sociedad. Explica que el actor es titular solo de 33 acciones en la sociedad y no de 8.554 como pretende, según se justifica de la historia de la conformación societaria que reseña. Además, indica que el demandante no ha acompañado el título de sus acciones inscritas en el registro de accionistas, único medio de prueba autorizado para acreditar las acciones que posee. Frente a ello, la señora juez titular del tribunal señalado en el acápite primero de esta expositiva, por sentencia de fecha siete de enero de dos mil once, desestimó tanto la demanda principal como la reconvencional.

Apelado dicho fallo por el actor, una sala de la Corte de Apelaciones de Antofagasta, por decisión de dos de junio de dos mil once, que se lee a fojas 334, la confirmó. En contra de esta última determinación, la parte ya individualizada, dedujo recurso de casación en el fondo, basado en los artículos 160, 426 y $384 \mathrm{~N}^{\circ} 1$ del Código de Procedimiento Civil, en relación con el artículo 1698 del Código Civil; 79, 81, 83 y 84 de la Ley 18.046; artículo 12 incisos $2^{\circ}$ y $3^{\circ}$ y 15 de la misma Ley en relación con los artículos 15 y 17 de su Reglamento.

El recurrente explica que constituye un hecho de la causa la titularidad por parte del actor de 8.554 acciones en la sociedad demandada a la época en que se acordó el pago de los dividendos, de manera que se habrían cometidos los yerros a las normas reguladoras de la prueba, contenidas en los artículos 160, 426 y $384 \mathrm{~N}^{\circ} 1$ del Código de Procedimiento Civil. Sostiene que a la luz de estos antecedentes, sería innecesario exigir acreditar que estas se encontraban inscritas en el registro de accionistas, en los términos del inciso final del artículo 81 de la Ley 18.046.

Funda su alegación en la inexactitud o falta de realidad del contenido recogido en el Registro de accionistas, lo que habría sido acreditado a partir de ciertos documentos aparejados al mismo y de la declaración del testigo don Rodrigo Marín Eterovic, abogado de la sociedad a esa época. El testigo indicado manifestó categóricamente que en su momento los traspasos aludidos se inscribieron en el señalado registro. Sus dichos reúnen los requisitos del artículo 426 del Código de Procedimiento Civil, constituyendo plena prueba, a la luz de lo dispuesto en el artículo $384 \mathrm{~N}^{\circ}$ 1 del mismo cuerpo de leyes, desde que se trata de la declaración de un testigo imparcial y verídico, que en su momento representó los intereses tanto del demandante como de los demás accionistas. 
Por lo demás -añade- la junta general extraordinaria de accionistas celebrada el 2 de junio de 2008 se menciona a Claudio Alejandro González Tassara como accionista, de manera que esta realidad no puede ser desconocida por acto jurídico alguno ni menos en un proceso judicial, cuya prueba se regula mediante la tasación que hace el legislador y que no escapa a los hechos evidentes, ni siquiera desconocidos en calidad de tal por los miembros que integran la sociedad. En seguida, se denuncia la vulneración de lo dispuesto en los artículos 79, 81, 83 y 84 de la Ley 18.046, sobre Sociedades Anónimas.

Asevera, conforme al hecho inamovible fijado por los jueces del grado, que da cuenta que el demandante es dueño del $42.5 \%$ de la totalidad de las acciones de la sociedad demandada, resulta evidente que correspondía, ante tal declaración, acoger la demanda. Sin embargo, al concluir la sentencia cuestionada que los derechos del socio no se encontraban inscritos en el registro de accionistas, y con ello el rechazo de la demanda, transgrede las normas citadas, desde que se ha pasado por alto que la sociedad demandada, es una sociedad anónima cerrada, que desde sus inicios se encuentra constituida únicamente por tres socios: la actual gerenta de la sociedad, Sra. Ana María Barón Parra; la presidenta de la misma, su hija, doña Sandra Vallejo Barón y el demandante, ex cónyuge de la señora Barón Parra.

En este sentido, a la época de la demanda, su parte desde larga data era propietario del caudal de acciones que reclama, las que fueron inscritas en el registro de accionistas que se llevaba en la época, esto es, en el año 1996. Lo anterior es un hecho asentado y de una lógica absoluta, lo que no solo se concluye de la declaración del testigo Marín Eterovic, quien fue abogado de la sociedad desde su inicio hasta el ańo 2006, sino además porque estas fueron inscritas, precisamente bajo la administración del propio actor, quien hasta el año 2006, fue el único gerente general de la compañía.

Fundamenta su recurso en lo prescrito por el Art. 81 y 83 de la Ley 18.046. Luego, también se contraviene lo dispuesto en el artículo 83 de la Ley en cuestión, que prescribe que la copia certificada por Notario del acta de la junta que haya acordado el pago de los dividendos y el o los títulos de las acciones o el documento que haga sus veces, en su caso, constituyen título ejecutivo en contra de la sociedad para demandar el pago de los dividendos, todo ello sin perjuicio de las demás acciones y sanciones judiciales o administrativas que corresponde aplicar en su contra y en la de los administradores. Entonces, si la ley no ha exigido ejecutivamente que se acredite la inscripción en el registro de accionistas, con mayor razón en el caso de autos, en que se encuentra comprobado que el demandante es titular de las acciones cuyos dividendos reclama por lo que resulta absolutamente procedente demandar en un juicio ordinario de 
cobro de pesos el pago de esos dividendos, máxime ellos fueron acordados en una junta de accionistas válidamente celebrada.

En un último capítulo, el recurrente alega la errada aplicación de los artículos 12 , incisos $2^{\circ}$ y $3^{\circ}$ y 15 de la Ley sobre Sociedades Anónimas y de los artículos 15 y 17 de su reglamento. En lo que respecta al inciso $3^{\circ}$ del citado artículo 12, afirma que dicha disposición resulta exclusivamente aplicable a las sociedades anónimas abiertas, en que la Superintendencia de Valores y Seguros tiene la facultad de resolver administrativamente las dificultades que se producen con la tramitación e inscripción del traspaso de acciones. Empero, la sociedad demandada de una sociedad anónima cerrada, que no ha optado por someterse al control y fiscalización de dicho organismo, de manera que en el ámbito jurisdiccional, los accionistas a quienes les afecta la negativa de la sociedad a inscribir sus acciones, han debido recurrir a la acción de protección para enmendar este acto arbitrario. Lo que como se ha señalado, no es menester realizar en estos autos, dado que las acciones de que se trata fueron debidamente inscritas en la administración anterior.

Sobre la infracción al artículo 15 tanto de la Ley 18.042 como de su reglamento, expresa que la primera disposición de la Ley aludida, regula la cesión de acciones. En autos, dicha cesión se materializó de acuerdo a las formalidades que estatuye la norma, las que fueron debidamente inscritas en el registro de la época. En definitiva, la solemnidad que impone este artículo, es precisamente necesaria para que se efectúe la tradición de las acciones. Luego, el artículo 17 del Reglamento de Sociedades Anónimas, en su inciso primero, vigente a la época, prescribía que la inscripción debía ser realizada por el gerente al momento de tomar conocimiento de la cesión o a más tardar dentro de las 24 horas siguientes. En este caso, las acciones de su parte fueron efectivamente inscritas $y$, por ende, cualquier argumentación contraria vulnera el tenor de esta norma, puesto que los títulos de dominio de las acciones vienen de la época en que el actor era el único gerente de la sociedad, quien efectuó las respectivas inscripciones.

La Corte Suprema consideró para resolver el hecho que el proceso no consta la inscripción de las acciones del demandante en el Registro de Accionistas de la sociedad demandada. Que en consideración a la situación fáctica descrita, la sentencia cuestionada reprodujo y confirmó el fallo de primer grado, rechazando la demanda. Para decidir así, los jueces de la instancia consideraron que, conforme a la regla del onus probandi correspondía a la demandante justificar su calidad de accionista, el derecho a percibir dividendos y, el devengo de tal derecho, en términos tales que exista acuerdo expreso de la junta de accionistas o utilidades líquidas aprobadas por la misma y que, no obstante haber satisfecho la primera de las cargas probatorias, esto es, que detenta la titularidad del $42 \%$ de las acciones de la sociedad demandada, concluyen que no se puede acceder 
al pago de los dividendos que reclama, desde que para la procedencia de dicho reparto se requiere que los derechos de los socios se encuentren inscritos en el registro de accionistas con la antelación que el artículo 81 de la Ley 18.046 prescribe, sin que en el proceso el actor haya comprobado el cumplimiento de tal formalidad legal mediante la prueba idónea para ello, esto es, el registro de accionista de la sociedad demandada.

Agrega que lo reseñado pone de manifiesto que el quid de la crítica de ilegalidad dirigida contra la sentencia que se impugna en el recurso, estriba en la inobservancia de las normas probatorias que, correctamente aplicadas, habría llevado a los jueces del fondo a tener por demostrada la inscripción de las acciones del actor en el registro de accionistas de la demandada, lo que por lo demás -según la tesis del recurrente- resulta innecesario, puesto que debe entenderse satisfecha la exigencia legal para cobrar y percibir el pago de dividendos con la sola demostración de la calidad de accionista, lo que al constituir un hecho de la causa, hace procedente el pago que se reclama.

Por otra parte, la Excma. Corte Suprema señala que el artículo 160 del Código de Procedimiento Civil, consagra la regla fundamental que en el ámbito procesal sujeta a los tribunales a fallar lo alegado y probado por los litigantes, salvo aquellos casos en que la ley los autorice para proceder de oficio; luego, se trata de un precepto ordenatorio litis que, en tal carácter, no da base para deducir un recurso de casación en el fondo. Mirando los basamentos del arbitrio de casación de la actora, es manifiesto que conciernen a la esfera probatoria de la contienda, circunstancia que hace necesario recordar que, en general, la doctrina y la jurisprudencia han caracterizado a este medio de impugnación como uno de índole extraordinaria, que no constituye instancia jurisdiccional, pues no tiene por finalidad propia revisar las cuestiones de hecho del pleito ya tramitado, sino antes que ello, se trata de un recurso de derecho, puesto que la resolución del mismo debe limitarse en forma exclusiva a examinar la correcta o incorrecta aplicación de la ley en la sentencia que se trata de invalidar, respetando los hechos que vienen dados en el fallo, que habrán sido fijados soberanamente por los jueces sentenciadores. En ese sentido, por disposición de la ley, el examen y consideración de tales hechos y de todos los presupuestos fácticos previos en que se apoya la decisión que se revisa, escapan al conocimiento del tribunal de casación.

En forma excepcional, es posible conseguir la alteración de los hechos asentados por los tribunales de instancia en caso que la infracción de ley que se denuncia en el recurso responda a la transgresión de una o más normas reguladoras de la prueba, mas no respecto de alguna de aquellas que reglan la apreciación de las probanzas que se hubiesen rendido, cuya aplicación es facultad privativa del juzgador.

Con todo, solo a algunas de las normas tocantes al ámbito en referencia se les reconoce el carácter de esenciales respecto de la actividad 
probatoria y son aquellas que estatuidas objetivamente en la ley, esto es, sin referir al criterio o decisión subjetiva de los magistrados que aquilatan los antecedentes $y$, precisamente, en ese entendido, justifican la intervención del tribunal de casación. Tales preceptos se reconocen pues su conculcación se da en las siguientes circunstancias: a) al aceptar un medio probatorio que la ley prohíbe absolutamente o respecto de la materia de que se trata; b) por el contrario, al rechazar un medio que la ley acepta; c) al alterar el onus probandi o peso de la prueba, esto es, en quien queda radicada la carga de aportar los elementos que acreditan los hechos que conforman la litis; d) al reconocer a un medio de prueba un valor distinto que el asignado en forma imperativa por el legislador o hacerlo sin que se cumplan los supuestos determinados como regla general por el legislador; e) igualmente, a la inversa, al desconocer el valor que el legislador asigna perentoriamente a un elemento de prueba, cuando este cumple efectivamente los supuestos legales, y f) al alterar el orden de precedencia en que deben ser llamados los medios probatorios y que la ley les asignare, en su caso.

Visto lo anterior desde el ángulo inverso, en la medida que los jueces del fondo respeten esas pautas elementales de juzgamiento, son soberanos para apreciar la prueba y, en consecuencia, sus decisiones no son susceptibles de ser revisadas por la vía de la casación, tanto en cuanto se basen en la justipreciación de los diversos elementos de convicción. De este modo, queda excluido de los contornos de la casación, lo atinente a la ponderación comparativa de una misma clase de medio probatorio o la apreciación que se realiza en conjunto de todas las probanzas; salvedad que se apoya en el componente básico de prudencia en la decisión que exhibe la actividad jurisdiccional, por cuanto las determinaciones que adoptan los jueces, si es que acatan estos preceptos que rigen la prueba, les otorgan libertad para calibrar los diversos elementos de convicción; quehacer situado al margen del examen que se realiza por la vía de casación de fondo. La razón de lo descrito reside en la justificación de la verdad de los hechos controvertidos en un juicio, llevado a efecto en la forma dispuesta por el legislador del ramo.

Que aproximando el raciocinio a las demás normas cuyo quebrantamiento se denuncia y, primeramente, sobre una eventual vulneración del artículo 1698 del Código Civil -norma que prescribe en su inciso primero que incumbe probar las obligaciones o su extinción al que alegan aquellas o esta- cabe tener presente que se trata de una disposición que exhibe el cariz referido en el razonamiento que precede y sobre la cual esta Corte ha decidido ya que su infracción se configura en la medida que el fallo altere el peso de la prueba, pues el precepto impone imperativamente esta carga, como regla general, a quien alega la existencia de la obligación o a su extinción. 
Mirando los antecedentes a través de esa óptica, se advierte que, para efectos de conformar o no los fundamentos de la demanda del actor a los presupuestos de la acción impetrada, se desprende que la sentencia impugnada exigió del demandante justificar la titularidad de las acciones que invoca; la inscripción de las mismas en el registro pertinente y el acuerdo de reparto de dividendos. Por lo mismo, al asignar así el peso probatorio, es claro que el fallo no ha incurrido en infracción alguna. Más bien, de los argumentos expuestos por la recurrente se desprende que lo reprochado al fallo es haber concluido que no acreditó el segundo supuesto de su acción -inscripción de sus derechos de la forma anotada- aseverando que tal carga fue satisfecha con la prueba rendida.

Tal pretendido yerro no dice relación con la infracción al artículo 1698 citado, sino que a una cuestión que le resulta ajena, puesto que se refiere a la apreciación del mérito de un medio probatorio específico.

Por otra parte, la Excma. Corte señala que respecto a la imputación de una errada ponderación de la prueba testimonial rendida en autos, cabe consignar que el artículo 384 del Código de Procedimiento Civil -disposición que se dice infringida en el recurso- mirado desde el ángulo propuesto en el libelo de nulidad, no reviste la naturaleza de ser reguladora de la prueba. Esta aserción deriva de una interpretación que emana de la historia fidedigna del establecimiento del precepto, a la que ha de acudirse con arreglo a lo consignado en la segunda parte del artículo 19 del Código Civil ${ }^{2}$. Por lo anterior, no queda sino entender que los tribunales de la instancia obran con independencia al apreciar la prueba de testigos -entendida como el análisis que efectúan de ellas los sentenciadores del grado para determinar cada uno de los elementos que consagra el legislador a objeto de regular su fuerza probatoria- labor que se encuentra entregada a dichos jueces y escapa al control del Tribunal de Casación.

Que del modo en que se ha venido razonando y en atención a los términos propuestos en la controversia, la médula de las consideraciones

2 En efecto, la Comisión Revisora del Proyecto de Código de Procedimiento Civil consideró las reglas de la citada disposición legal como principios generales para los jueces, circunstancia que precisaría luego la Comisión Mixta y al efecto puede citarse que el senador señor Ballesteros expuso que "debería dejarse amplia libertad al tribunal para apreciar el mérito probatorio de las declaraciones de testigos, como quiera que en realidad constituyen solo una presunción, en el sentido lato de la palabra. El señor Vergara recuerda que así lo ha sostenido en otras ocasiones en que se ha tratado de cuestiones relacionadas con la apreciación de la prueba. De tal manera que, a su juicio, el tribunal debiera estar facultado para desestimar, no solo el dicho de dos, sino de cualquier número de testigos, cuando en su concepto no fueren dignos de fe sus testimonios. La Comisión aceptó las ideas de los señores Ballesteros y Vergara y para consignarlas en el proyecto se acordó reemplazar las palabras "hará" que emplea el número $2^{\circ}$ por la frase "podrá constituir". (Los Códigos Chilenos Anotados. Código de Procedimiento Civil -Conforme a la Edición Reformada de 1918- Orígenes, Concordancias, Jurisprudencia, Santiago Lazo, Poblete-Cruzat Hermanos Editores, 1918, páginas 338 a 342); 
que condujeron a los sentenciadores de la Corte de Apelaciones a confirmar la decisión del a quo y, consecuencialmente a rechazar la demanda, lo fue justamente la interpretación acorde a los postulados que se han desarrollado en este fallo, en orden al hecho indiscutido de no haberse acreditado por parte del actor la inscripción de las acciones de que es titular en el Registro de Acciones de la sociedad demandada, en los términos que prescribe la ley, lo que le impide reclamar en este proceso el pago de los dividendos acordados. Que, por consiguiente, los errores de derecho en que se ha fundado el presente recurso de casación en el fondo, no se han cometido del modo postulado por el recurrente, razón por la que su arbitrio de nulidad, por fuerza, habrá de ser desestimado.

\section{3) ANÁliSIS DEL CASO}

\section{a. Valor de la inscripción en el Registro de Accionistas}

El fallo en referencia sostiene que la calidad de socio se obtiene por medio de inscripción en el Registro de Accionistas, de manera tal que aquella tiene un valor constitutivo. Ello se condice y cimienta en lo preceptuado en los artículos 62 de la LSA, al disponer que "Solamente podrán participar en las juntas y ejercer sus derechos a voz y voto, los titulares de acciones inscritas en el Registro de Accionistas con cinco dias de anticipación a aquel en que haya de celebrarse la respectiva junta", y el artículo 81 de la LSA que en su inciso final señala: "Los dividendos serán pagados a los accionistas inscritos en el registro respectivo el quinto dia hábil anterior a las fechas establecidas para su solución".

A ello debemos agregar lo establecido en los artículos 34 y 10 del Reglamento de $\mathrm{SA}^{3}$. La primera disposición señala que "La adquisición de las acciones suscritas por el titular se produce al momento en que se inscriban las acciones a su nombre en el Registro de Accionistas, momento desde el cual se adquiere la calidad de accionista". Por su parte, el siguiente precepto señala que "cada vez que sea necesario determinar a qué accionistas corresponderá un determinado derecho social, se considerarán aquellos que se encuentren inscritos en el Registro de Accionistas a la medianoche del quinto dia hábil anterior a aquel desde el cual pueda ejercerse el derecho. En el caso de las sociedades anónimas cerradas para los efectos de participar en las juntas de accionistas, se considerará a aquellos que figuren inscritos en el Registro de Accionistas al inicio de la respectiva junta”.

\footnotetext{
3 El Reglamento de las sociedades anónimas citado en el fallo fue modificado por DS de Hacienda No 702, de 2011, que entró en vigor en el año 2012.
} 
La inscripción debe practicarse en el Registro de Accionistas que cada sociedad debe tener. La apertura del Registro de Accionistas se efectuará el día del otorgamiento de la escritura de constitución. Este Registro podrá llevarse por cualquier medio, siempre que este ofrezca seguridad de que no podrá haber intercalaciones, supresiones o adulteraciones que puedan afectar su fidelidad.

La inscripción de las acciones es necesaria para ejercer los derechos y obligaciones de ser accionista. Si no se acredita la inscripción en los términos que prescribe la ley, ello impide reclamar en este proceso el pago de los dividendos acordados. Tal omisión trae aparejada la inoponibilidad del acto a la sociedad y, con ello, que el actor no pueda ser considerado como accionista, en cuanto le permite ejercer los derechos inherentes a tal calidad.

Afirmado la inoponibilidad descrita, la Corte Suprema, con fecha 25 de marzo de 2008, en causa Julio Ernesto Ahumada con Sociedad de Transportes Servicios y Comercial San Bernardo SA 4 , señaló:

"Si la acción adquirida por el cesionario demandante nunca fue inscrita en el registro de accionistas, esta es una cuestión que en su momento debió ser resuelta entre cesionario y cedente de acuerdo a las obligaciones recíprocas que adquirieron al celebrar la cesión. En consecuencia, la referida cesión de derechos realizada entre el legítimo dueño de la acción en su calidad de cedente y el actor cesionario no produce efectos respecto de la sociedad ni de terceros. Quien nunca ha detentado la calidad de socio de la empresa demandada y por consiguiente no ha tenido los beneficios y obligaciones que ella impone, no puede alegar perjuicios basados en esa calidad ni exigir su pago de la sociedad a la que no le empece la cesión de la acción, por lo que no procede acoger la petición de declarar el derecho a recibir una indemnización de perjuicios".

\section{b. Calidad de socio. Nacimiento de sus derechos:}

El accionista es tal por ser titular de acciones en una sociedad. Sobre el particular, la Excma. Corte declara muy bien que, en término generales y como una manera de aproximarse a la resolución del asunto, debe tenerse en cuenta que la acción en el Derecho Societario ${ }^{5}$ se identifica con

4 Corte Suprema. 25 de marzo de 2008. "Julio Ernesto Ahumada con Sociedad de Transportes Servicios y Comercial San Bernardo SA". En base de datos de: www.legalpublishing.cl; $\mathrm{N}^{\circ}$ LegalPublishing: 39139 [fecha de visita 6 de septiembre de 2011].

5 Véase: Puga Vial, Juan Esteban (2011). La sociedad Anónima, y otras sociedades por acciones en el derecho Chileno y comparado. Santiago de Chile: Editorial Jurídica de Chile; VásQuez Palma, M. Fernanda (2013) Sociedades. Comerciantes, empresas, grupos de empresas y otros sujetos del Derecho comercial. Santiago de Chile: Editorial LegalPublishing-Thomson Reuters. 
un derecho subjetivo inmaterial, inserta en la categoría de bienes muebles, a la luz de la distinción que en la materia hace el Código de Bello.

De acuerdo a las reglas del derecho común, para efectuar la transferencia de acciones entre vivos, no hay discusión que se requiere un título traslaticio de dominio y un modo de adquirir, en este caso, la tradición. Así, el único modo de adquirir acciones por actos entre vivos -que no sea la suscripción de las mismas- será la cesión. Esta última debe estar precedida de un título traslaticio, como la compraventa, permuta o dación, no exigiéndose en esta materia, según lo expresado en el motivo que antecede, ningún tipo de solemnidad para su conclusión. Las normas especiales se refieren a la tradición. El documento en que se materializa la cesión se denomina compraventa o traspaso, donde el título y el modo de adquirir pueden estar contenidos en un mismo instrumento.

No cabe duda que la cesión de acciones produce efectos entre cedente y cesionario por la sola celebración del acto entre las partes, esto es, desde la formación del consentimiento, lo que corresponderá a aquella oportunidad en que se suscribió el instrumento por ambas partes y, por lo tanto, respecto del cedente, el adquirente es el accionista de la sociedad y el titular de los derechos que emanan de la acción. En este caso, el título marca el principio de los efectos de la cesión entre las partes que lo celebran. Empero, para el perfeccionamiento de la cesión, la situación difiere en relación a los terceros, donde cobran relevancia las solemnidades que rodean la tradición -traspaso-, apartándose del régimen propio de los bienes muebles contemplado en el artículo 684 del Código Civil. Su eficacia frente a terceros, distintos al cedente y cesionario, dependerá de su anotación en el Registro de Accionistas de la sociedad, tal como perentoriamente se dispone en el Reglamento ("La cesión de las acciones producirá efecto respecto de la sociedad y de terceros desde que se inscriban en el Registro de Accionistas...").

Que en esta línea argumentativa, las transferencias de acciones requieren, además de un contrato causal entre las partes, su posterior inscripción en el libro de Registro de Acciones, sin la cual no es posible constituir la titularidad accionaria para el interés de la sociedad anónima $y$, en general, para terceros. La norma ha sido interpretada por la doctrina en el sentido que tal inclusión de la cesión en el registro -inscripción- no se instituye con carácter meramente declarativo, sino que informa una exigencia de tipo constitutivo, como lo es la inscripción conservatoria respecto del dominio de los inmuebles, desde que se produce la constitución del dominio o de otro derecho real, tanto para el titular, como para la sociedad y terceros. Por ello, la sola trasferencia, sin anotación en el Registro, no alcanza para reputar excluido al vendedor o cedente desde los socios de una sociedad anónima.

Entonces, el título solo representa el derecho del accionista y la inscripción, la constitución del derecho de dominio, "que constituye por lo 
demás, el antecedente básico del principio registral de tracto sucesivo o continuo, tendiente a que la serie de anotaciones registrales esté debidamente encadenada, de suerte que cada acto de disposición aparezca derivado de la voluntad del titular inscrito"6.

Bajo esta lógica, la C.S., con fecha 27 de noviembre de 1991, en causa Dońa Javiera Inversiones S.A. con Bolsa de Comercio de Santiago sobre Recurso de protección ${ }^{7}$, sentenció:

"La inscripción que se practica en un registro de accionistas tiene un carácter constitutivo puesto que constituye el dominio y a la vez lo prueba por sí misma. El acto de registro es un acto jurídico causal que, por lo mismo, atiende a la causa o motivo, es decir al título o antecedente de la adquisición. Por lo mismo, la causa, que ha de examinarse y calificarse, debe consistir en un acto válido y legítimo. El principio registral denominado de la "calificación" puede definirse como la función jurídica determinativa de la inscripción y su contenido o bien de su reprobación o rechazo".

De este modo, la formalidad de inscripción no solo opera como un medio de prueba sino que también como una vía de publicidad con "fides publica".

Que íntimamente ligado con los raciocinios que preceden y como corolario de los mismos, es menester dejar asentado que la ley distingue entre la adquisición o transferencia de acciones (suscripción o cesión) y, el título de las mismas. El artículo 11 del reglamento pormenoriza las menciones que deben contener los títulos de acciones. Sin embargo, el título carece de relevancia en cuanto a su vinculación con la sociedad, ya que su sola tenencia margina al accionista de los derechos elementales que asisten a los que se encuentran inscritos, según ya se adelantó (Art. 41 Regl.). Luego, el título de la acción per se e incluso, el accionista como cesionario, cuyas acciones no han ingresado al Registro de Acciones, no confieren los derechos que la ley reserva para aquellos que sí las han inscrito, lo que no obsta a que no pueda hacer exigibles los derecho que emanan del título traslaticio pero limitado a las partes del mismo.

\section{c. Sobre la obligación de inscribir}

Más allá de concordar con el análisis descrito, existe un punto relevante que lamentablemente no fue parte de la discusión precedente. Se

6 Así también lo ha reconocido la Corte de Santiago, Rol 6852-2003, "Summun Empresarial S.A. con Sociedad Marketmar S.A."

7 Corte Suprema. 27 de noviembre de 1991. Sobre Recurso de protección caratulada "Doña Javiera Inversiones S.A. con Bolsa de Comercio de Santiago". En base de datos de: www. microjuris.com; RDJ2709, MJJ2709 [fecha de visita 29 de agosto de 2011]. 
trata de la obligatoriedad de practicar la inscripción y las repercusiones que dicha omisión tiene.

En la presente causa no estuvo en tela de juicio la tenencia de acciones en la sociedad, sino más bien la falta de inscripción de las mismas, por lo que la interrogante es por qué no lo estaban. Frente a ello, debemos considerar que de acuerdo al Art. $7^{\circ}$ del Reglamento citado, la sociedad anónima deberá llevar un Registro de Accionistas en el que anotará, a lo menos, el nombre, domicilio y cédula nacional de identidad o rol único tributario de cada accionista, si lo tuviera, la serie, si la hubiere, y el número de acciones de que sea titular, la fecha en que estas se hayan inscrito a su nombre y, tratándose de acciones suscritas y no pagadas, la forma y oportunidades de pago de ellas. Este Registro debe abrirse el mismo día del otorgamiento de escritura de constitución. El Registro de Accionistas podrá llevarse por cualquier medio, siempre que este ofrezca seguridad de que no podrá haber intercalaciones, supresiones u otra adulteración que pueda afectar su fidelidad (Art. 9o Regl.).

Tanto la ley como el reglamento establecen que a la sociedad no le corresponde pronunciarse sobre la transferencia de las acciones y está obligada a inscribir sin más trámite los traspasos que se le presenten, a menos que no se ajusten a las formalidades que establecen los artículos precedentes (Art. 40 Regl.) ${ }^{8}$.

En tal sentido, en un fallo reciente sobre esta materia, la Corte $\mathrm{Su}$ prema, con fecha 9 de marzo de 2012, en causa "Luis Castro Montt con Compañía de Cervecerías Unidas SA CCU S.A.; de Tanner Corredores de Bolsa SA y Fernando Morelli Bonilla"9, sentenció:

Por este camino, la Corte de Apelaciones de Santiago, con fecha 13 de julio de 1999, en causa Astete Bascuñán, Alfonso y otros con Cía. de Teléfonos de Chile S.A., sobre Recurso de apelación y Recurso de casación en la forma, sentenció: "Según la Ley 18.046 de Sociedades Anónimas y su reglamento, a la sociedad no le corresponde pronunciarse sobre la transferencia de acciones y está obligada a inscribir sin más trámite, los traspasos que se le presenten. No obstante la sociedad deberá verificar que se haya efectuado por medio de una escritura privada verdadera o auténtica, firmada por el cedente y el cesionario ante dos testigos o ante Notario público, lo que obliga a la compañía a la verificación, examen y comprobación de los aspectos formales del traspaso con los títulos de las acciones según su registro. El término verificación consiste en la acción de verificar, probar si una cosa es verdadera; consiste también en examinar la verdad de una cosa y también salir cierto y verdadero lo que se dijo o pronosticó. Verificar por su parte, es probar que una cosa que se dudaba es verdadera y comprobar o examinar la verdad de una cosa. Examinar es inquirir, escudrińar con diligencia, cuidado una cosa, reconocer la calidad de una cosa, viendo si contiene algún defecto o error. Comprobar, por su parte es verificar confirmar la veracidad o exactitud de alguna cosa y finalmente, revisar es ver con atención y cuidado. Para los efectos de ulterior asiento o registro, el traspaso de acciones no se basta a sí mismo, o sea, no basta una observación visual de simple hábito. En consecuencia la empresa que falta a sus obligaciones, permitiendo el traspaso fraudulento de las acciones, incurre en responsabilidad extracontractual".

9 Corte Suprema. 9 de marzo de 2012. Rol 3549-2011. "Luis Castro Montt con Compañía de Cervecerías Unidas SA CCU S.A.; de Tanner Corredores de Bolsa SA y Fernando Morelli 
"Frente a un traspaso de acciones que se le presente, la sociedad deberá velar porque las formas del mismo sean las adecuadas, tomando los recaudos necesarios para cautelar la fidelidad de los datos que en definitiva registre. En caso contrario, vendría prácticamente garantizada la recurrencia con que cualquiera pudiese arrogarse la facultad de vender acciones ajenas, bajo el mero expediente de contar con un instrumento que cumpla con los requisitos externos que señala el Artículo 15 del Reglamento en mención. Los fundamentos por los cuales en los recursos se dicen infringidas las normas sustantivas de la responsabilidad contractual y extracontractual, lo mismo que aquellas referentes a los deberes impuestos a las Sociedades Anónimas en el estatuto legal y reglamentario que las gobierna y a las obligaciones que habrían pesado sobre la corredora demandada, se han visto superados por el núcleo fáctico determinado en el fallo, que pone el acento en el incumplimiento de los deberes legales de la sociedad demandada, ergo, incorporados al vínculo asociativo habido entre esta última y el tercero de los demandados, como asimismo, en la negligencia evidenciada por este último en los actos que culminaron en la confección de una nueva ficha del referido accionista para el registro. Estos hechos constituyen la razón central del acogimiento a favor del actor de la compensación en el valor bursátil de las acciones de que fuera titular y que, fruto del proceder que se reprocha a las recurrentes, terminaron siendo traspasadas y ulteriormente transferidas, sin que el verdadero accionista concurriera a la ejecución del negocio.

Al pedirse la declaración de nulidad del traspaso de acciones de la litis emplazando únicamente a la sociedad emisora, al corredor de bolsa y a una persona natural cuyas funciones concernían de manera gravitante en la regularidad del registro de accionistas, se ha dejado de abarcar al sujeto pasivo que por antonomasia debía responder al alegato de nulidad: el cesionario o comprador adquirente de los títulos traspasados. Por consiguiente, aún en caso que esta Corte concordara con quienes recurren, en cuanto a la existencia de un vicio que autorizaba la declaración de nulidad absoluta, de todos modos habría debido rechazarse la demanda, dado que no es posible acoger la nulidad impetrada si no fueron emplazadas todas las partes con derechos sustanciales comprometidos en la contienda (considerandos $28^{\circ}, 29^{\circ}$ y $32^{\circ}$ de la sentencia de la Corte Suprema)".

La cesión de acciones producirá efecto respecto de la sociedad desde el momento de la inscripción en el Registro de Accionistas. La sociedad

Bonilla”. En base de datos de: www.legalpublishing.cl, CL/JUR/542/2012. [fecha de visita 18 de mayo 2012]. 
practicará la inscripción en el momento que tome conocimiento de la cesión. Los interesados podrán acreditar que la sociedad ha tomado conocimiento de la cesión en mérito a una notificación practicada por un corredor de bolsa o notario público, quienes en el acto de la notificación deberán entregar una copia del contrato de cesión y el título de las acciones, a menos que este último estuviese en poder de la sociedad o no tuviere obligación de imprimir láminas físicas de los títulos (Art. 41 Regl.).

La sociedad deberá archivar los traspasos, poderes y demás documentos en mérito de los cuales practicó cualquier inscripción o anotación en el Registro de Accionistas. Los documentos relacionados a las personas que son accionistas de la Sociedad deberán mantenerse archivados mientras dichas personas conserven la calidad de accionistas. Los documentos relacionados con personas que dejen de ser accionistas podrán ser destruidos en los plazos y cumpliendo los requisitos establecidos en ley $\mathrm{N}^{\circ} 18.845$ que establece sistemas de microcopia o micrograbación de documentos (Art. 43 Regl.).

De este modo, la obligación de inscribir las acciones recae en la sociedad. Si esta no cumple con dicha obligación, la ley no prevé de manera particular una forma de cumplimiento o sanción. En la práctica, se ha optado por la interposición de recursos de protección, fundamentados en el resguardo del Derecho a la propiedad. Así, por ejemplo ocurrió en la causa "Carrizo Corvacho, Teresa c/ Sociedad Agrícola del Norte S.A.", en que la Primera Sala de la Corte de Apelaciones de Arica, que al pronunciarse sobre una cancelación de inscripción, expresó con fecha 31 de agosto de $2012^{10}$ :

"El artículo 19 No 24 de la Constitución Política de la República, asegura a todas las personas el derecho de propiedad en sus diversas especies sobre toda clase de bienes corporales o incorporales. La cancelación de inscripción en el registro de accionistas ha vulnerado el artículo citado, que ampara el derecho de propiedad en sus diversas especies sobre bienes corporales e incorporales, ello de conformidad a lo dispuesto en el artículo 583 del Código Civil que dispone que sobre las cosas incorporales hay también una especie de propiedad, resultando con ello indudable que, ser propietario de acciones de una sociedad anónima, también se encuentra protegida por el precepto constitucional.

Acordar la cancelación de las inscripciones en una Junta Extraordinaria de Accionistas es arbitrario e ilegal. Ilegal, ya que no encuentra norma o fundamento legal en que se funde, es más, contraviene la garantía constitucional consagrada en el artículo 19 No 3 inciso 5 de la Constitución Política de la República, que prohíbe ser juzgado por 
Comisiones Especiales, con lo que, en la especie, se infringió el artículo 19 No 3 inciso $5^{\circ}$ de la Constitución Política de la República”.

\section{d. Sociedades cerradas ajenas a supervisión}

Ligado con lo anterior, debemos reflexionar en otro aspecto relevante y que dice relación con el hecho que las sociedades anónimas cerradas están carentes de supervisión de manera general. Este dato no es menor si se considera que la normativa de las sociedades anónimas regula a sus tres tipos (abiertas, especiales y cerradas) con cercana intensidad, sin embargo, solo las dos primeras están afectas a control por parte de la SVS. En otras palabras, las obligaciones impuestas a las sociedades anónimas cerradas podrían dejar de cumplirse y ello no ser observado más que por los accionistas.

De acuerdo al Art. 12 de la Ley de SA, la Superintendencia resolverá administrativamente, con audiencia de las partes interesadas, las dificultades que se produzcan con motivo de la tramitación e inscripción de un traspaso de acciones. Para el caso de las cerradas no existe una norma semejante.

Lo anterior nos lleva a preguntarnos indefectiblemente por la razón de mantener bajo un mismo régimen legal a dos tipos societarios que no comparten la misma fisonomía. En efecto, ciertamente, las sociedades anónimas abiertas distan notablemente de las cerradas en las que en realidad debiera primar cuotas mayores de autonomía de la voluntad por no estar envueltos intereses públicos o de terceros, a diferencia de las anteriores que debido a su forma de transacción de sus acciones requieren un mayor control.

Así, por ejemplo, podemos contraponer esta regulación a un tipo societario más afín de las sociedades anónimas cerradas, como son las sociedades por acciones. La normativa que regula a estas últimas plantea la exigencia de un Registro en que se anotará, a lo menos, el nombre, domicilio y cédula de identidad o rol único tributario de cada accionista, el número de acciones de que sea titular, las fechas en que estas se hayan inscrito a su nombre y tratándose de acciones suscritas y no pagadas, la forma y oportunidades de pago de ellas (...). En caso de que algún accionista transfiera el todo o parte de sus acciones, deberá anotarse esta circunstancia en el registro de que trata este artículo (Art. 431 Cco.). La diferencia resulta evidente en cuanto si bien aquí se plantea un sistema registral, este no tiene valor constitutivo en cuanto a la calidad de socio, como ocurre en las sociedades anónimas cerradas.

Por otra parte, el inciso final de la citada norma establece una responsabilidad especial para este tipo societario, al disponer que los administradores y el gerente general de la sociedad serán solidariamente 
responsables de los perjuicios que causaren a accionistas y a terceros con ocasión de la falta de fidelidad o vigencia de las informaciones contenidas en el registro a que se refiere este artículo. Si nos detenemos en los fundamentos de este precepto, seguramente llegaremos al resguardo necesario que debe brindarse a los accionistas y terceros frente a una sociedad que no se encuentra fiscalizada en su actuar. Derivado de ello, surge como natural inquietud si tal razonamiento no debiera también aplicarse a las sociedades anónimas cerradas pues, al igual que las sociedades por acciones, no se encuentran afectas a supervisión salvo casos muy concretos.

En este contexto, surge una reflexión mayor que consiste en preguntarse si es necesario regular a las sociedades anónimas cerradas bajo el mismo texto normativo que para las anónimas abiertas. En mi opinión tal pregunta debe necesariamente responderse en términos negativos, pues con ello se tiende a no reconocer las diferencias que entre ambos tipos habitan. Las sociedades anónimas cerradas debieran presentar una regulación de orden preponderantemente dispositivo, tal como ocurre con las sociedades por acciones. Esta realidad obliga a discernir su especial arquitectura legal ${ }^{11}$, distanciándose en muchos aspectos de las sociedades abiertas.

\section{4) BibliografíA}

- Puga Vial, Juan Esteban (2011) La sociedad anónima, y otras sociedades por acciones en el derecho chileno y comparado. Santiago de Chile: Editorial Jurídica de Chile.

- Vásquez Palma, M. Fernanda (2013) Sociedades. Comerciantes, empresas, grupos de empresas y otros sujetos del Derecho comercial. Santiago de Chile: Editorial LegalPublishing-Thomson Reuters.

\section{JURISPRUDENCIA}

- Corte Suprema. 27 de noviembre de 1991. Sobre Recurso de protección caratulada "Doña Javiera Inversiones S.A. con Bolsa de Comercio de Santiago". En base de datos de: www.microjuris.com; RDJ2709, MJJ2709, [fecha de visita 29 de agosto de 2011].

- Corte Suprema. 25 de marzo de 2008. "Julio Ernesto Ahumada con Sociedad de Transportes Servicios y Comercial San Bernardo SA". En base de datos de: www.legalpublishing.cl; $\mathrm{N}^{\circ}$ Legal Publishing: 39139, [fecha de visita 6 de septiembre de 2011].

11 A mayor abundamiento, véase VÁsQUEZ (2013). 
- Corte Suprema. 9 de marzo de 2012. Rol 3549-2011. "Luis Castro Montt con Compañía de Cervecerías Unidas SA CCU S.A.; de Tanner Corredores de Bolsa SA y Fernando Morelli Bonilla”. En base de datos de: www.legalpublishing.cl, CL/JUR/542/2012. [fecha de visita 18 de mayo 2012]. 